\title{
First case of endoscopic ultrasound-guided gastrojejunal anastomosis for duodenal stricture in refractory Crohn's disease: a bridge toward inflammation control
}

Endoscopic ultrasonography-guided gastrojejunal anastomosis (EUS-GJA) was developed in 2015 using a lumen-apposing metal stent (LAMS) [1, 2]. Its application was described for malignant bowel obstruction and a few cases of benign obstruction $[3,4]$. Crohn's disease is an inflammatory bowel disease that could induce inflammatory or fibrotic bowel strictures, the management of which includes medical therapy, endoscopic dilation or surgical resection [5]. We report a case of duodenal stricture in severe Crohn's disease and short bowel syndrome.

A 51-year-old man presented with a repeat episode of bowel obstruction complicating severe Crohn's disease. Medical history included short bowel syndrome due to surgically resected strictures. In June 2017, after failure of medical optimization, the multidisciplinary inflammatory bowel disease team proposed EUS-GJA.

EUS-GJA was performed with $\mathrm{CO}_{2}$ insufflation by an endoscopist expert ( $\triangleright$ Video 1). There was no adverse event. A liquid diet was started for 48 hours, followed by a mixed diet for the next 5 days. The patient was discharged 1 week later. Medical therapy with infliximab $(10 \mathrm{mg} / \mathrm{kg})$ and methotrexate was started at the same time.

Between August and September 2017, the patient had two recurrences of occlusion downstream of the LAMS, confirmed by computed tomography ( $\triangleright$ Fig. 1). The first recurrence was managed by endoscopic dilation through the LAMS ( $\triangleright$ Fig. 2 ), and the second by covered enteric stent (\$Fig.3). In January 2018, endoscopy showed spontaneous migration of all stents (two enteral, one LAMS) into the stomach, and spontaneous closure of the GJA. After 1 year of follow-up, the patient recovered a normal duodenal pathway and inflammatory dis-

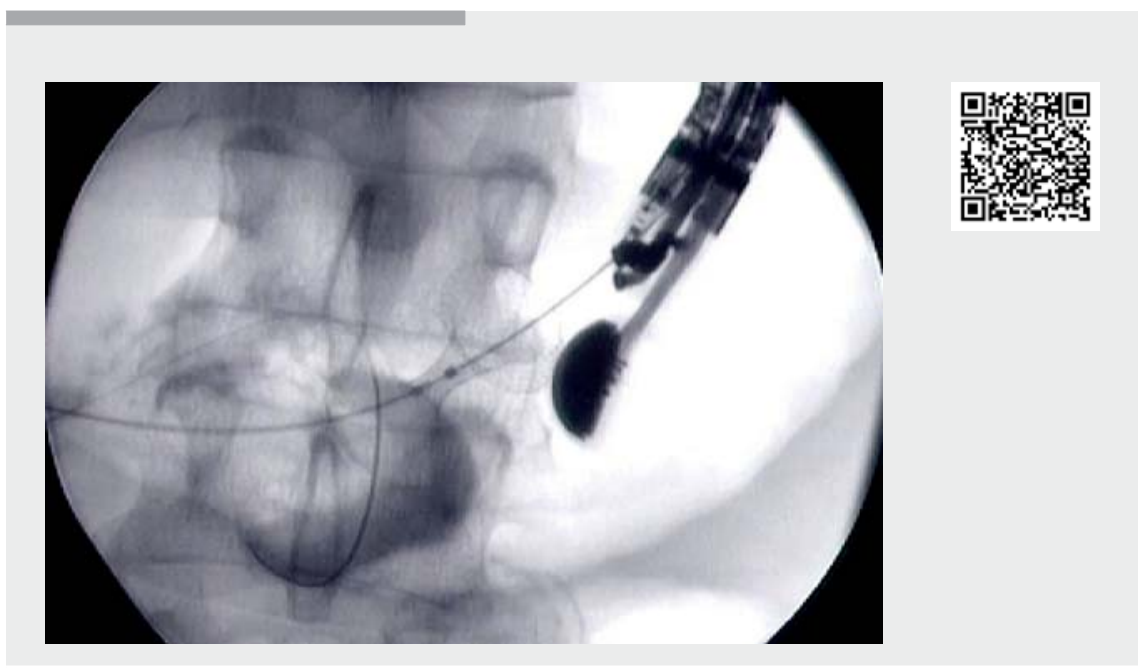

$\checkmark$ Video 1 Endoscopic management of a symptomatic duodenal stricture in refractory and severe Crohn's disease with endoscopic ultrasound-guided gastrojejunal anastomosis.
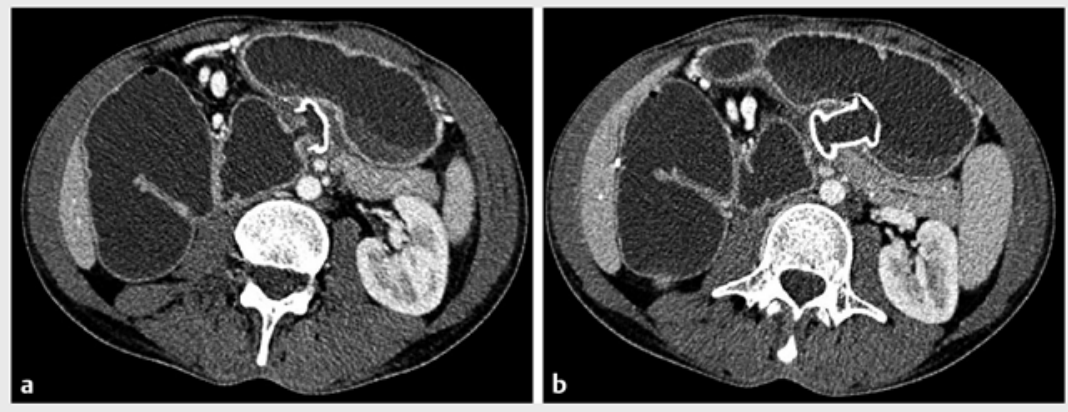

- Fig. 1 Computed tomography view. a Recurrence of duodenal occlusion downstream of the lumen-apposing metal stent (LAMS). b Gastrojejunal anastomosis with LAMS.

ease was controlled with medical therapy. This case suggests a new application of LAMS for EUS-GJA in a benign indication. For refractory stricture in Crohn's disease with short bowel syndrome, EUS-GJA allowed management of bowel occlusion until inflammatory disease was stabilized by medical treatment.

Endoscopy_UCTN_Code_TTT_1AS_2AB

\section{Competing interests}

Prof. Barthet and Dr. Gonzalez are consultants for Boston Scientific. Dr. Serrero is a consultant for AbbVie, Takeda, and Janssen, and speaker for AbbVie, Takeda, Janssen, and MSD. 


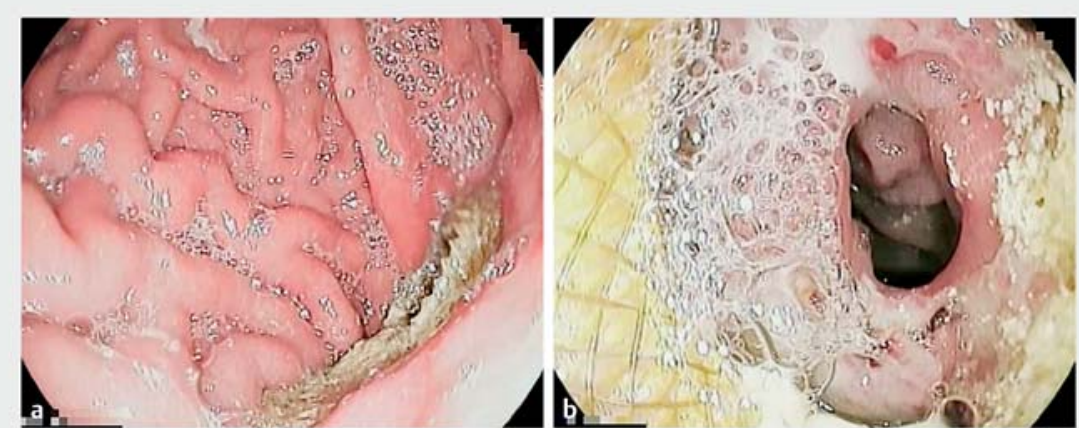

- Fig. 2 Endoscopic view of the gastrojejunal anastomosis. a Proximal flange of the lumenapposing metal stent (LAMS) in the stomach. $\mathbf{b}$ Visualization of the jejunum through the LAMS.

The authors

Laurent Monino ${ }^{1,2}$, Jean-Michel Gonzalez ${ }^{2}$, Melanie Serrero ${ }^{2}$, Marc Barthet ${ }^{2}$

1 Department of Hepatogastroenterology, Université Catholique de Louvain, Cliniques Universitaires Saint-Luc, Brussels, Belgium

2 Department of Hepatogastroenterology, Assistance Publique des Hôpitaux de Marseille, Aix-Marseille Université, Hôpital Nord, Marseille, France

\section{Corresponding author}

\section{Laurent Monino, MD}

Department of Hepatogastroenterology, AP-HM, Aix-Marseille Université, Hôpital Nord, Chemin des Bourrely, 13015 Marseille, France

Fax: +33-4-91968737

laurent.monino@uclouvain.be

\section{References}

[1] Barthet M, Binmoeller KF, Vanbiervliet G et al. Natural orifice transluminal endoscopic surgery gastroenterostomy with a biflanged lumen-apposing stent: first clinical experience (with videos). Gastrointest Endosc 2015; 81: 215-218

[2] Khashab MA, Kumbhari V, Grimm IS et al. EUS-guided gastroenterostomy: the first U.S. clinical experience (with video). Gastrointest Endosc 2015; 82: 932-938

[3] Tyberg A, Perez-Miranda M, Sanchez-Ocaña $R$ et al. Endoscopic ultrasound-guided gastrojejunostomy with a lumen-apposing metal stent: a multicenter, international experience. Endosc Int Open 2016; 04: E276-E281

[4] Rimbaş M, Larghi A, Costamagna G. Endoscopic ultrasound-guided gastroenterostomy: Are we ready for prime time? Endosc Ultrasound 2017; 6: 235

[5] Gionchetti P, Dignass A, Danese S et al. 3rd European evidence-based consensus on the diagnosis and management of Crohn's disease 2016: Part 2: Surgical management and special situations. J Crohns Colitis 2017; 11: $135-149$

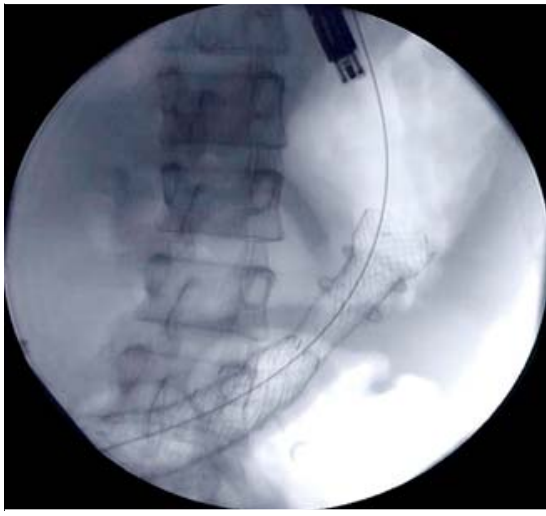

- Fig. 3 Endoscopic management of occlusive recurrence with a covered enteric stent through the lumen-apposing metal stent.

\section{Bibliography}

DOI https://doi.org/10.1055/a-1066-4488

Published online: 13.12.2019

Endoscopy 2020; 52: E204-E205

(c) Georg Thieme Verlag KG

Stuttgart · New York

ISSN 0013-726X

\section{ENDOSCOPY E-VIDEOS}

https://eref.thieme.de/e-videos

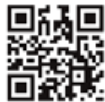

Endoscopy E-Videos is a free access online section, reporting on interesting cases and new

techniques in gastroenterological endoscopy. All papers include a high quality video and all contributions are freely accessible online.

This section has its own submission website at https://mc.manuscriptcentral.com/e-videos 